ORIGINAL ARTICLE

\title{
Risk factors among handgun retailers for frequent and disproportionate sales of guns used in violent and firearm related crimes
}

\author{
G J Wintemute, P J Cook, M A Wright
}

Injury Prevention 2005;11:357-363. doi: 10.1136/ip.2005.009969

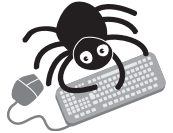

Additional data can be found on our website.

See end of article for authors' affiliations

Correspondence to: Dr G J Wintemute, Violence Prevention Research Program, University of California, Davis, 2315 Stockton Boulevard, Sacramento, CA 95817, USA; giwintemute@ucdavis.edu

Accepted 12 October 2005
Objective: To determine the retailer and community level factors associated with frequent and disproportionate sales of handguns that are later used in violent and firearm related crimes (VFC handguns).

Design: Cross sectional. The authors used California records to identify all handguns sold by study subjects during 1996-2000 and federal gun tracing records to determine which of these guns had been recovered by a police agency in the US or elsewhere and traced by 30 September 2003.

Subjects and setting: The 421 licensed gun retailers in California selling at least 100 handguns annually during 1996-2000.

Main outcome measure: The number of VFC handguns per 1000 gun years of exposure. Differences are expressed as incidence rate ratios (RR) with $95 \%$ confidence intervals (CI).

Results: Subjects accounted for $11.7 \%$ of California retailers with handgun sales, $81.5 \%$ of handgun sales, and $85.5 \%$ of VFC handguns. Among subjects, the 3426 VFC handguns accounted for $48.0 \%$ of all traced handguns and $65.0 \%$ of those linked to a specified crime. The median VFC handgun trace rate was 0.5 / 1000 gun years (range 0-8.8). In multivariate analysis, this rate increased substantially for each singlepoint increase in the percentage of proposed sales that were denied because the purchasers were prohibited from owning guns (RR 1.43; $95 \% \mathrm{Cl} 1.32$ to 1.56), and was increased for pawnbrokers (RR 1.26; $95 \% \mathrm{Cl} 1.02$ to 1.55 ). Community level crime rates and sociodemographics had little predictive value.

Conclusions: Risk factors, largely determined at the retailer level, exist for frequent and disproportionate sales of handguns that are later used in violent and firearm related crimes. Screening to identify high risk retailers could be undertaken with data that are already available.
M ore than 291000 violent crimes involving guns, including an estimated 10657 homicides, were committed in the United States in $2004 .{ }^{12}$ Federally licensed retailers are an important source of the guns used in these crimes. Of people incarcerated during the 1990s for crimes involving guns, $12-19 \%$ of those in state prisons ${ }^{3}$ and $19 \%$ of those in federal prisons ${ }^{4}$ purchased their guns personally from a retail store or pawnshop. Corrupt licensed retailers are the immediate source of nearly half of all guns that are trafficked-diverted intentionally from legal to illegal commerce. ${ }^{5}$

Gun retailers in the US are also an important, if indirect, source of guns used in crime in other countries. An estimated 144000 to 199000 people die in firearm homicides worldwide each year (excluding deaths during armed conflict). More than half of these deaths occur in North America, Latin America, and the Caribbean. ${ }^{6}$ Some $80 \%$ of Mexico's illegal firearms and most recovered crime guns in major Canadian cities are imported illegally from the United States.

A retailer's importance as a source of crime guns can be estimated by the number of recovered crime guns that retailer had previously sold. Linking crime guns to retailers is accomplished by gun tracing: reconstructing a gun's chain of ownership from manufacture to first retail sale. Gun traces are conducted by the Bureau of Alcohol, Tobacco, Firearms and Explosives (ATF), which received 240651 trace requests in fiscal year 2002. ${ }^{8}$ With few exceptions, traced guns are known or suspected to have been used in crime. ${ }^{9}$

In 1998, just $1020(1.2 \%)$ of 83272 federally licensed retailers accounted for $57.4 \%$ of all guns traced by the ATF. ${ }^{10}$
Gun sales are also concentrated, however; approximately 15\% of retailers request $80 \%$ of background checks on gun buyers conducted by the National Instant Criminal Background Check System (NICS). ${ }^{11}$

It has therefore been argued that the number of crime guns traced to a retailer reflects nothing but that retailer's sales volume. ${ }^{12}$ Preliminary evidence suggests that this is incorrect. ${ }^{13}$ If instead there are high risk retailers who sell a disproportionate number of guns that are later used in crimes, and if status as a high risk retailer can be predicted, then new, evidence based opportunities for preventing gun violence may follow. We test these hypotheses for licensed gun retailers in California, focusing on handguns linked to violent and firearm related crimes (VFC handguns).

\section{METHODS}

The California Department of Justice (CDOJ) provided records for all handgun sales by licensed retailers during the study period and for proposed sales that CDOJ denied under laws prohibiting felons, violent misdemeanants, and certain others from purchasing firearms (see http://www. injuryprevention.com/supplemental for additional material). ATF provided records for all gun traces initiated during the study period (see additional material as before).

Abbreviations: ATF, Bureau of Alcohol, Tobacco, Firearms and Explosives; CDOJ, California Department of Justice; IQR, interquartile range; NICS, National Instant Criminal Background Check System; VFC, violent and firearm related crime. 
We linked the gun sales and gun trace datasets to identify all handguns that were sold by subject retailers and subsequently traced by ATF. We considered a match on gun manufacturer and serial number alone to be insufficient, as some manufacturers use serial numbers repeatedly. We declared a match when a handgun's manufacturer, serial number, type (for example, semiautomatic pistol), and caliber were identical. When one of the latter two variables was discordant, we compared records manually, reviewing handgun model designations if available and referring to standard catalogues $^{14}{ }^{15}$ when necessary, to determine whether the discordance was real or reflected an error in the data.

Though ATF traces terminate with a gun's first retail sale, at least $85 \%$ of recovered crime guns change hands after that sale and before their recovery by a police agency. ${ }^{9}$ To link each traced handgun to the retailer whose sale of the gun most closely preceded its recovery, we identified all sales of traced handguns occurring before the guns' recovery dates. Following an established procedure, ${ }^{16}$ we assigned a traced handgun to the retailer identified in the ATF trace when no subsequent sales were recorded. When there were subsequent sales, or when the trace record did not identify any seller and the sales records did, we assigned the gun to the most recent seller identified in the sales records (see http:// www.injuryprevention.com/supplemental).

Additional variables addressed specifics of each retailer's handgun sales. First was sales of inexpensive handguns (defined in table 1), which figure prominently among crime guns $^{9}{ }^{16}$ and purchasers of which have an increased incidence of subsequent arrest. ${ }^{17}$ Second was sales at gun shows, which have been implicated as important sources of crime guns. ${ }^{518} 19$ Third was sales of multiple guns in a single transaction, considered a marker for gun trafficking. ${ }^{5}$ Fourth was sales to police agencies or personnel, expected to have a negative relation with sales of crime guns.

We included retailer type, as pawnbrokers are believed to be disproportionately involved in sales of crime guns,,$^{20}$ and the number of study years during which each retailer sold handguns, as some corrupt retailers operate briefly, disappear, and resurface with a new identity (Pierce $G$, personal communication, 2000). We considered the percentage of purchasers who were male (males have higher crime rates than females do) and median purchaser age (criminal activity among adults generally decreases with age).

We also included the percentage of proposed sales that were denied by CDOJ. Most denials stem from previous

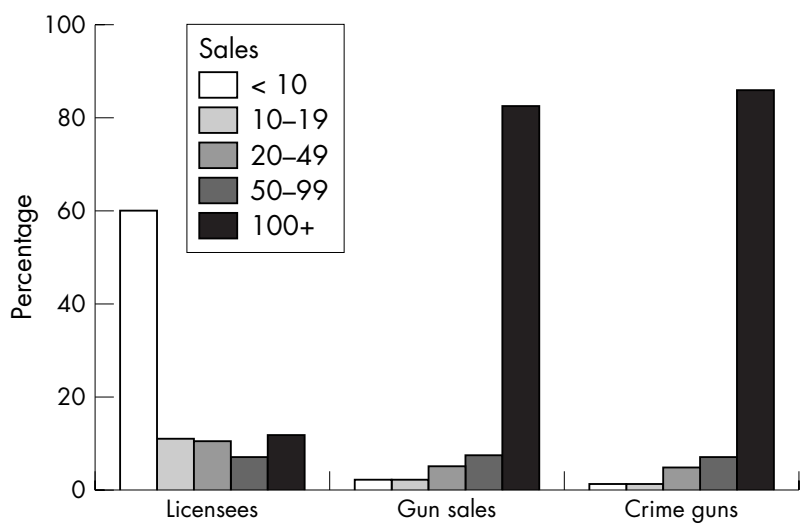

Figure 1 Percentages of federally licensed gun retailers, of handgun sales for 1996-2000, and of traces of handguns linked to violent and firearm related crimes for 1996-2003, that are attributable to retailers having specified average annual handgun sales. Retailers with approximately 100 sales annually are study subjects.
Table 1 Specific violent and firearm related crimes linked to 3426 handguns sold by study subjects

\begin{tabular}{lc}
\hline Crime & $\mathbf{n}(\%)$ \\
\hline Homicide & $241(7.0)$ \\
Assault & $570(16.6)$ \\
Robbery & $144(4.2)$ \\
Intimate partner or domestic violence & $142(4.1)$ \\
Rape or other sex crimes & $18(0.5)$ \\
Kidnapping & $12(0.4)$ \\
Firing a weapon in public & $72(2.1)$ \\
Carrying a concealed weapon & $558(16.3)$ \\
Illegal possession of a weapon & $1596(46.6)$ \\
Illegal gun commerce & $49(1.4)$ \\
Other* & $24(0.7)$ \\
\hline \multirow{2}{*}{ *Resisting an officer (3), arson (2), riot (1), extortion (1), crimes against } \\
person (17).
\end{tabular}

criminal convictions, ${ }^{21} 22$ and a high denial percentage might therefore reflect a clientele at increased risk for committing crimes. For retailers linked to traced handguns, we added the median time between the traced guns' sales and their recoveries by police, known as time to crime; a short time to crime is a marker for gun trafficking and is common among retailers selling many traced guns. ${ }^{9} 1623$

We represented local police policy on gun tracing by a binary variable, coded 1 if the retailer's city had a policy of tracing all recovered guns; such a policy would increase the probability of a recovered gun's being traced (see http:// www.injuryprevention.com/supplemental).

All other variables were measured at the county level. These included the number of firearm licensees with handgun sales per 100000 adults in 2000, under the hypothesis that increased density would increase competition and thereby increase sales of crime guns. We evaluated year 2000 violent Crime Index crime rates, as higher rates might reflect an increased supply of crime guns for tracing. ${ }^{24}$ We considered year 2000 arrest rates for weapons offenses, which are largely possession offenses (crime rates were not available, and arrest rates might also reflect police efforts to confiscate guns at risk for use in crimes). ${ }^{24}$ Finally, we included year 2000 census data for seven sociodemographic variables shown to account for $60-70 \%$ of small area variation in serious violent crime rates ${ }^{25} 26$ (see http:// www.injuryprevention.com/supplemental).

In addition to handguns linked to violent crimes, our outcome measure included handguns traced in connection with such crimes as illegally carrying a concealed weapon and illegal weapon possession. Such handguns are at increased risk of being used in violence, and police initiatives targeting such guns have reduced violent crime rates. ${ }^{27-29}$ We also included handguns linked to crimes involving illegal gun commerce, such as obliterating a serial number or trafficking.

\section{Statistical analysis}

Our primary outcome measure was the number of VFC handguns sold by each retailer. We conducted a separate analysis using all traced handguns.

We used medians and interquartile ranges (IQRs) to describe continuous variables. We used a binomial distribution to test the basic hypothesis that random variation alone could account for observed differences in our outcome measure.

The dependent variable in all regressions was the number of traced handguns linked to each retailer. Poisson regressions demonstrated overdispersion, and our analysis therefore relied on negative binomial regression. ${ }^{30}$

In regression analysis we replaced each retailer's absolute sales volume with an estimate of gun years of exposure to the 
Table 2 Descriptive statistics for count and continuous variables

\begin{tabular}{|c|c|c|c|}
\hline Variable & Median & IQR & Range \\
\hline \multicolumn{4}{|l|}{ Variables measured at the retailer level } \\
\hline VFC handgun traces*, $\mathrm{n}$ & 3 & $1-8$ & $0-184$ \\
\hline Total handgun traces, $\mathrm{n}$ & 5 & $2-15$ & $0-336$ \\
\hline VFC traces per 1000 gun years of exposure & 0.5 & $0.2-0.9$ & $0.0-8.8$ \\
\hline Total traces per 1000 gun years of exposure & 1.1 & $0.6-2.0$ & $0.0-14.2$ \\
\hline Handgun sales, $\mathrm{n}$ & 945 & $557-2002$ & $108-24035$ \\
\hline Gun years of exposure, $n$ & 4869 & $2862-10272$ & $566-129906$ \\
\hline Years with sales, $\mathrm{n}$ & 5 & $4-5$ & $1-5$ \\
\hline Gun years from sales of inexpensive handguns, \%† & 2.6 & $1.0-6.9$ & $0.0-75.7$ \\
\hline Gun years from sales at gun shows, \%‡ & 0.2 & $0.0-1.1$ & $0.0-86.9$ \\
\hline Gun years from police sales, \%§ & 5.6 & $3.7-8.2$ & $0.2-88.4$ \\
\hline Gun years from sales of multiple guns, \% & 9.4 & $7.0-12.3$ & $0.0-58.8$ \\
\hline Deniás, \% (of sales + denials) & 1.1 & $0.6-1.5$ & $0.0-5.4$ \\
\hline Median time to crime for VFC handguns, $y^{* *}$ & 2.4 & $1.8-3.3$ & $0.1-7.2$ \\
\hline Median age of purchasers, $y$ & 41 & $39-43$ & $24-53$ \\
\hline Male purchasers, $\%$ & 93.3 & $91.5-94.6$ & $79.6-99.2$ \\
\hline 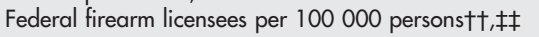 & 8.1 & $4.5-14.3$ & $0.3-58.3$ \\
\hline \multicolumn{4}{|l|}{ Crime rates per 100000 personst† } \\
\hline Homicide & 4.8 & $2.8-8.1$ & $0.0-10.5$ \\
\hline Rape & 29.0 & $27.2-34.0$ & $11.2-70.4$ \\
\hline Robbery & 118.9 & $88.3-209.3$ & $10.6-448.0$ \\
\hline Aggravated assault & 345.2 & $297.9-516.8$ & $129.3-607.8$ \\
\hline Felony weapons offenses§§ & 46.2 & $44.5-59.2$ & $20.6-113.5$ \\
\hline Misdemeanor weapons offenses $\uparrow$ & 12.6 & $11.2-18.7$ & $3.7-41.4$ \\
\hline \multicolumn{4}{|l|}{ Sociodemographics †† } \\
\hline Black population, $\%$ & 5.7 & $1.9-9.8$ & $0.3-14.9$ \\
\hline Latino population, $\%$ & 30.8 & $19.0-44.0$ & $5.5-72.2$ \\
\hline Males ages $20-29$, as $\%$ of males ages $40-44$ & 187 & $165-208$ & $99-284$ \\
\hline Unemployed people, \% (of people ages $\geqslant 16$ ) & 4.4 & $3.4-5.0$ & $1.9-7.8$ \\
\hline Households headed by single females, $\%$ & 12.2 & $10.9-14.7$ & $3.9-17.1$ \\
\hline Median household income, $\times \$ 1000$ & 42.4 & $42.1-54.1$ & $27.5-74.3$ \\
\hline Households per 10000 persons & 3292 & $3247-3566$ & $2651-4322$ \\
\hline \multicolumn{4}{|c|}{ 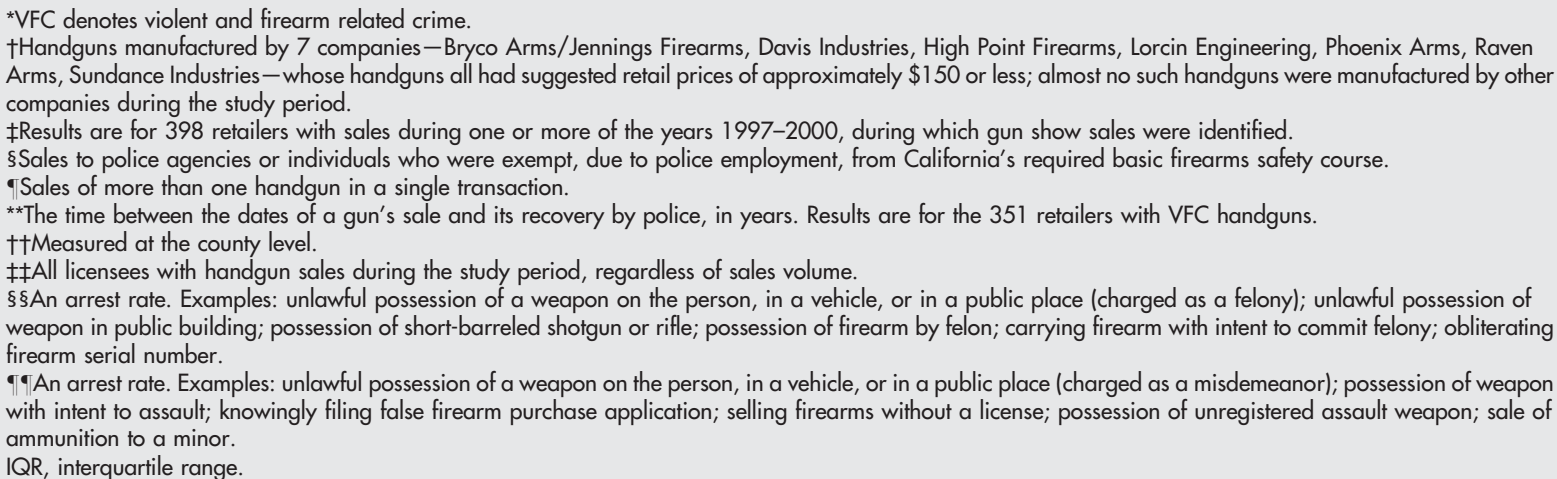 } \\
\hline
\end{tabular}

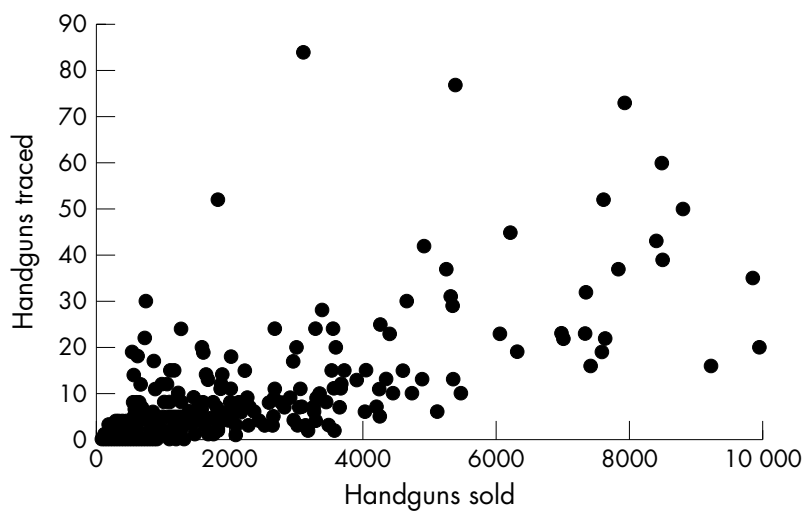

Figure 2 Number of handguns sold during 1996-2000, and number of traces of those handguns linked to violent and firearm related crimes during 1996-2003, for study subjects. (Six outlier observations have been removed: four with $>16000$ sales and two with $>200$ traces. These observations were included in the regression analysis.) risk of being traced for that retailer's handguns, analogous to replacing a count of people with person years in a cohort study. Variables representing sales of inexpensive guns, of multiple guns, at gun shows, and to police personnel were expressed as percentages of total gun years of exposure. We included (gun years of exposure/1000) as an offset variable ${ }^{30}$ (see http://www.injuryprevention.com/supplemental).

We first performed bivariate regressions. Variables with $\mathrm{p}<0.10$ in these regressions were entered into multivariate models in which community level variables were added in groups to variables measured at the retailer level. Reduced models were generated by removing variables from the full multivariate models in order of decreasing $p$ until all remaining variables had $\mathrm{p}<0.10$. We exponentiated regression coefficients and expressed differences as rate ratios for traced handguns per 1000 gun years of exposure.

The study was approved by the UC Davis institutional review board.

\section{RESULTS}

Study subjects are the 421 California retailers, including 390 $(92.6 \%)$ gun dealers and 31 (7.4\%) pawnbrokers, who sold handguns during 1996-2000 and had average annual sales of 
Table 3 Results of regressions on individual explanatory variables for traced handguns linked to violent and firearm related crimes, and for all traced handguns*

\begin{tabular}{|c|c|c|c|c|c|c|}
\hline \multirow[b]{2}{*}{ Variable } & \multicolumn{3}{|c|}{$\begin{array}{l}\text { Handguns linked to violent and firearm } \\
\text { related crimes }\end{array}$} & \multicolumn{3}{|c|}{ All traced handguns } \\
\hline & $\mathbf{R R}$ & $95 \% \mathrm{Cl}$ & p Value & $\mathbf{R R}$ & $95 \% \mathrm{Cl}$ & p Value \\
\hline \multicolumn{7}{|l|}{ Variables measured at the retailer level } \\
\hline Gun years of exposure, $\times 1000$ & 1.01 & $1.00-1.01$ & 0.18 & 1.01 & $1.00-1.01$ & 0.04 \\
\hline Years with handgun sales, $\mathrm{n}$ & 1.06 & $0.98-1.16$ & 0.16 & 1.06 & $0.99-1.14$ & 0.12 \\
\hline Gun years from sales of inexpensive handguns, $\%$ & 1.03 & $1.02-1.05$ & $<0.0001$ & 1.03 & $1.02-1.04$ & $<0.0001$ \\
\hline Gun years from sales at gun shows, \%† & 1.00 & $0.99-1.00$ & 0.21 & 1.00 & $0.99-1.00$ & 0.33 \\
\hline Gun years from police sales, $\%$ & 0.98 & $0.97-0.99$ & $<0.0001$ & 0.98 & $0.98-0.99$ & $<0.0001$ \\
\hline Gun years from sales of multiple guns, $\%$ & 1.03 & $1.01-1.04$ & 0.004 & 1.02 & $1.01-1.04$ & 0.004 \\
\hline Denials, \% (of sales + denials) & 1.81 & $1.66-1.97$ & $<0.0001$ & 1.71 & $1.59-1.85$ & $<0.0001$ \\
\hline Median time to crime for traced guns, y & 0.83 & $0.77-0.90$ & $<0.0001$ & 0.85 & $0.79-0.91$ & $<0.0001$ \\
\hline Median age of purchasers, $y$ & 0.91 & $0.89-0.93$ & $<0.0001$ & 0.92 & $0.90-0.93$ & $<0.0001$ \\
\hline Male purchasers, $\%$ & 0.92 & $0.90-0.95$ & $<0.0001$ & 0.93 & $0.91-0.96$ & $<0.0001$ \\
\hline Retailer type (pawnbroker $=1$, gun dealer $=0$ ) & 1.75 & $1.28-2.38$ & 0.0004 & 1.78 & $1.36-2.32$ & $<0.0001$ \\
\hline \multicolumn{7}{|l|}{ Variables reflecting local gun commerce and tracing policy } \\
\hline Federal Firearm Licensees per 100000 people§ & 0.94 & $0.92-0.95$ & $<0.0001$ & 0.94 & $0.93-0.95$ & $<0.0001$ \\
\hline Retailer's city traces all recovered guns (yes $=1$ ) & 3.05 & $2.25-4.14$ & $<0.0001$ & 2.82 & $2.14-3.70$ & $<0.0001$ \\
\hline \multicolumn{7}{|l|}{ Crime rates per 100000 people§ } \\
\hline Homicide & 1.16 & $1.14-1.19$ & $<0.0001$ & 1.15 & $1.12-1.17$ & $<0.0001$ \\
\hline Rape & 1.00 & $0.99-1.02$ & 0.97 & 1.00 & $0.99-1.02$ & 0.58 \\
\hline Robbery & 1.01 & $1.01-1.01$ & $<0.0001$ & 1.01 & $1.01-1.01$ & $<0.0001$ \\
\hline Aggravated assault & 1.00 & $1.00-1.00$ & $<0.0001$ & 1.00 & $1.00-1.00$ & $<0.0001$ \\
\hline Felony weapons offenses & 1.00 & $0.99-1.00$ & 0.20 & 1.00 & $0.99-1.00$ & 0.28 \\
\hline Misdemeanor weapons offenses & 0.96 & $0.94-0.98$ & $<0.0001$ & 0.96 & $0.94-0.97$ & $<0.0001$ \\
\hline \multicolumn{7}{|l|}{ Sociodemographics§ } \\
\hline Black population, $\%$ & 1.13 & $1.11-1.16$ & $<0.0001$ & 1.13 & $1.11-1.15$ & $<0.0001$ \\
\hline Latino population, $\%$ & 1.03 & $1.03-1.04$ & $<0.0001$ & 1.03 & $1.02-1.03$ & $<0.0001$ \\
\hline Unemployed people, \% (of people ages $\geqslant 16$ ) & 1.11 & $1.03-1.20$ & 0.008 & 1.06 & $0.99-1.14$ & 0.096 \\
\hline Households headed by single females, $\%$ & 1.21 & $1.16-1.27$ & $<0.0001$ & 1.18 & $1.14-1.23$ & $<0.0001$ \\
\hline Males ages $20-29$, as $\%$ of males ages $40-44$ & 1.01 & $1.01-1.01$ & $<0.0001$ & 1.01 & $1.01-1.01$ & $<0.0001$ \\
\hline Median household income, $\times \$ 1000$ & 0.99 & $0.98-1.00$ & 0.003 & 0.99 & $0.98-1.00$ & 0.08 \\
\hline Households per 10000 people & 1.00 & $1.00-1.00$ & $<0.0001$ & 1.00 & $1.00-1.00$ & $<0.0001$ \\
\hline
\end{tabular}

*Gun years of exposure/1000 is employed as an offset variable; results are on a per 1000 gun year basis.

†Results are for retailers with sales during one or more of the years 1997-2000, during which gun show sales were identified.

$\ddagger$ Results for all retailers with traced handguns: 351 subjects in the case of VFC handguns and 392 for all traced handguns.

$\S$ Measured at the county level.

Arrest rate.

$\mathrm{RR}$, rate ratio; $\mathrm{Cl}$, confidence interval.

at least 100 handguns during their year(s) in business. These retailers made up $11.7 \%$ of all 3611 California retailers selling handguns during that time but accounted for $81.5 \%$ of handgun sales ( 781475 of 959 189) and $85.5 \%$ of handguns traced in connection with a violent or firearm related crime (3426 of 4006) (fig 1). VFC handguns accounted for $48.0 \%$ (3426 of 7133) of handguns traced to study subjects and
$65.0 \%$ (3426 of 5271) of traced handguns linked to a specified crime (table 1).

Table 2 presents descriptive statistics. Of 421 retailers, 351 $(83.4 \%)$ were linked to at least one VFC handgun, but just 10 retailers accounted for $29.2 \%$ of VFC handguns traced to study subjects. Thirty one subjects $(7.4 \%)$ were in cities with mandatory tracing policies. Of the 3426 VFC handguns, 2926

Table 4 Results for reduced multivariate regression models for traced handguns linked to violent and firearm related crimes, and for all traced handguns*

\begin{tabular}{|c|c|c|c|c|c|c|}
\hline \multirow[b]{2}{*}{ Variable } & \multicolumn{3}{|c|}{$\begin{array}{l}\text { Handguns linked to violent and firearm } \\
\text { related crimes }\end{array}$} & \multicolumn{3}{|c|}{ All traced handguns } \\
\hline & $\overline{R R}$ & $95 \% \mathrm{Cl}$ & p Value & $\overline{R R}$ & $95 \% \mathrm{Cl}$ & p Value \\
\hline \multicolumn{7}{|l|}{ Variables measured at the retailer level } \\
\hline Gun years from police sales, $\%$ & 0.99 & $0.99-1.00$ & 0.04 & 0.99 & $0.99-1.00$ & 0.007 \\
\hline Gun years from sales of multiple guns, $\%$ & & & & 1.01 & $1.00-1.02$ & 0.07 \\
\hline Denials, \% (of sales + denials) & 1.43 & $1.32-1.56$ & $<0.0001$ & 1.37 & $1.28-1.47$ & $<0.0001$ \\
\hline Median age of purchasers, $y$ & 0.95 & $0.94-0.97$ & $<0.0001$ & 0.95 & $0.94-0.96$ & $<0.0001$ \\
\hline Retailer type (pawnbroker $=1$, gun dealer $=0$ ) & 1.26 & $1.02-1.55$ & 0.03 & 1.30 & $1.10-1.53$ & 0.002 \\
\hline \multicolumn{7}{|c|}{ Variables reflecting local gun commerce and tracing policy } \\
\hline Federal Firearm Licensees per 100000 people† & 0.97 & $0.96-0.98$ & $<0.0001$ & 0.97 & $0.96-0.98$ & $<0.0001$ \\
\hline Retailer's city traces all recovered guns (yes $=1$ ) & 1.43 & $1.15-1.78$ & 0.001 & 1.52 & $1.28-1.79$ & $<0.0001$ \\
\hline \multicolumn{7}{|l|}{ Crime rates per 100000 people } \\
\hline Robbery & 1.00 & $1.00-1.00$ & 0.003 & 1.00 & $1.00-1.00$ & $<0.0001$ \\
\hline \multicolumn{7}{|l|}{ Sociodemographics $\dagger$} \\
\hline Latino population, \% & 1.01 & $1.00-1.02$ & 0.07 & & & \\
\hline
\end{tabular}

*Gun years of exposure/1000 is employed as an offset variable; results are on a per 1000 gun year basis. Time to crime was not incorporated in these models. †Measured at the county level.

$\mathrm{RR}$, rate ratio; $\mathrm{Cl}$, confidence interval. 
(85.4\%) were recovered in California; other leading recovery states were Texas ( 74 guns, $2.2 \%$ ), New York ( 51 guns, $1.5 \%$ ), Nevada (46 guns, 1.3\%), and Arizona and Illinois (each with 29 guns, $0.8 \%$ ).

The number of VFC handguns linked to retailers with similar sales volumes varied substantially (fig 2). Each handgun had probability $\mathrm{p}=0.00438$ (3426 traces/781 475 sales) of being traced as a VFC handgun under the hypothesis that this probability was the same for all handguns sold. Forty seven retailers (11.2\%) had VFC handgun traces numerous enough to be inconsistent with this hypothesis $(p<0.05)$; accounting for $17.9 \%$ of sales and $46.1 \%$ of VFC handguns. The median VFC handgun trace rate for all retailers was 0.5/1000 gun years (IQR 0.2-0.9; range 0-8.8).

Table 3 presents bivariate regression results. Most retailer level variables were significant for both VFC handguns and all traced handguns, as were variables representing gun tracing policy and retailer density. Results for crime rates and sociodemographics were mixed. In multivariable models in which community level variables were added to retailer characteristics, effects of crime rates and sociodemographics were small and rarely significant (see supplementary table 1 at http://www.injuryprevention.com/supplemental).

In a reduced model (table 4), the VFC handgun trace rate increased substantially for every single point increase in the percentage of proposed sales that were denied (RR 1.43; $95 \%$ CI 1.32 to 1.56). Rates were increased for pawnbrokers (RR 1.26 ; $95 \%$ CI 1.02 to 1.55 ) and for retailers in cities with mandatory tracing policies (per year RR 1.43 ; 95\% CI 1.15 to 1.78). The trace rate was inversely related to police sales, median purchaser age, and retailer density, but these effects were small. Crime rates and sociodemographics were not significant predictors of VFC handgun trace rates, except for a small increase with the robbery rate. Very similar results were obtained for all traced handguns (table 4).

For the 351 retailers with VFC handgun traces (see supplementary table 2 at http://www.injuryprevention.com/ supplemental), trace rates were negatively, but not significantly, associated with time to crime (per year RR 0.95; 95\% CI 0.90 to 1.01 ). The association with the percentage of male purchasers was negative and significant (per single point increase, RR 0.98 ; 95\% CI 0.95 to 1.00 ). Results for other variables were little changed.

In all analyses, interactions between retailer type and other retained variables were not significant (results not shown).

\section{DISCUSSION}

These findings suggest that handgun retailers' sales of guns that are later used in violent and firearm related crimes can be predicted, largely by factors measured at the retailer level.

There is a strong relation between sales of crime guns and prospective sales that are denied following a background check. This suggests that retailers who sell disproportionate numbers of crime guns also deal disproportionately with people who are at high risk of committing crimes with guns. Some of these people are prohibited from purchasing guns, usually because they have been convicted of serious crimes, and their detection by a background check increases denied sales for these retailers.

But others at high risk would not be prohibited people. Prior offenders are one such group. In much of the US, one can have an extensive criminal record involving lesser offenses and still purchase handguns. Handgun buyers with criminal records are at substantially increased risk of committing crimes subsequently, including violent and firearm related crimes. ${ }^{31}$ Still others who purchase from these retailers may be surrogates ("straw purchasers") for prohibited individuals or gun traffickers. ${ }^{5}$ Purchases by high risk, non-prohibited individuals and by surrogates would link these retailers to disproportionate sales of crime guns.

Some of our findings were unexpected. Gun show sales were not a risk factor for sales of crime guns in these data. California regulates gun shows to a unique degree, however, which may have reduced their otherwise considerable importance as sources of crime guns. ${ }^{18} 19$ Sales of crime guns were inversely related to the percentage of purchasers who were male-a finding that persisted in multivariate analysis for retailers linked to VFC handguns. Women may be more likely than men to act as surrogates; of straw purchasers working with gun trafficking operations, 18\% were girlfriends or spouses of the traffickers. ${ }^{5}$ The negative relation between crime gun sales and licensee density may reflect the higher density in rural counties ${ }^{32}$ than in urban areas where most gun traces originate.

Sociodemographics and local crime rates were generally not important predictors of crime gun sales. This could occur if most crime guns were recovered in communities distant and different from those where the retailers were located. But most crime guns are recovered close to their places of origin. ${ }^{9}{ }^{16} 23$ The results suggest that most important predictors of crime gun sales, other than local gun tracing policy, reflect characteristics of the retailers themselves.

We cannot state definitively whether retailers who sell a disproportionate number of crime guns do so through their own behavior or from circumstances beyond their control. Important factors could include practices that encourage patronage by high risk people, but also unmeasured attributes of the retailer's clientele (prior criminal history, for example) or location, the guns sold, or other matters.

Retailers who deliberately participate in illegal gun commerce are likely to be disproportionate sources of crime guns. Some such retailers may be missed in a records based study such as this; characteristics of corrupt retailers, such as selling guns without records, may represent clandestine behavior. ${ }^{193}$

Other limitations deserve mention. We could not include rifles and shotguns; CDOJ cannot archive records for these guns. The classification of handguns as inexpensive was based on manufacturer, as selling prices were unavailable. This classification would preferably have been restricted to new handguns, as used guns from other manufacturers could be inexpensive, but sales records did not reliably indicate whether guns were new or used.

Most importantly, these traced handguns are necessarily a subset of handguns sold by our subjects during 1996-2000 and used in crime. Not all crime guns are recovered, and not all recovered guns are traced. Police agencies vary in the likelihood that they will request gun traces, which affects the number of traced guns linked to individual retailers. In addition, selection bias may result if some guns are more likely to be traced than others. ${ }^{34}$ Most traced guns in California come from cities with mandatory tracing policies, so within-jurisdiction selection bias should be minimal. ${ }^{16}$ Handguns traced by these cities are similar to those from others in the state; ${ }^{16}$ selection bias may not be a major factor.

Some have argued that gun traces are inappropriate for research on gun related crime, as not all traced guns are linked to a specific crime. ${ }^{35}{ }^{36}$ Our results for all traced handguns were similar to those obtained for handguns linked to known violent and firearm related crimes. Such concern may not be justified.

The US Department of Justice has recently stressed the need to identify retailers who are disproportionate sources of crime guns. ${ }^{8}$ Our results confirm earlier suggestions that pawnbrokers merit special attention, ${ }^{20}$ though the mechanism for their increased sales of crime guns remains unclear. 
Nationwide comprehensive tracing of recovered crime guns would be valuable but will not occur soon. Our findings suggest that data already collected at the federal level could help identify these retailers. For each retailer, the Department of Justice could compare the number of background check queries submitted to the NICS with the number of denials to compute a denial percentage. ${ }^{37}$ (The number of queries would not equal the number of sales, as a transaction involving multiple guns generates one query, but the two would be closely correlated. Sales of multiple guns are reported separately to ATF.)

This denial percentage may be a useful initial screening tool, because sales of crime guns increase rapidly as it increases. Such screening and the focused enforcement efforts that result could help disrupt illegal gun commerce without unduly affecting the legitimate gun market in the US.

As part of global efforts to prevent violence involving small arms and light weapons, an international agreement is being negotiated to uniquely identify all firearms during manufacture and trace those that are recovered after illicit use. ${ }^{38}$ Our results show that gun tracing can help identify important sources of guns used in violent crimes and could have an international impact on the public's health and security. ${ }^{39} 40$

\section{ACKNOWLEDGEMENTS}

The authors are grateful to the Firearms Division, California Department of Justice, and the National Tracing Center, US Bureau of Alcohol, Tobacco, Firearms and Explosives. We thank Barbara Claire, Vanessa McHenry, Kevin Grassel, and Michael Romero for their expert technical assistance, and Stephen Teret and Jeri Bonavia for their helpful suggestions

\section{Authors' affiliations}

G J Wintemute, M A Wright, Violence Prevention Research Program, University of California, Sacramento, CA, USA

P J Cook, Sanford Institute of Public Policy, Duke University, Durham, NC, USA

Funding: this research was supported by grant 2002-IJ-CX-0005 from the National Institute of Justice. Preliminary work was supported by grants 1999-8827 and 2001-17381 from The David and Lucile Packard

\section{Key points}

- Just over $1 \%$ of licensed gun retailers sell nearly $60 \%$ of guns later used in crime; why this occurs has not been known. It has been argued that the number of crime guns sold by a retailer only reflects retailer's sales volume.

- Among licensed retailers of handguns in California, the number of guns sold was an inadequate predictor of the number of guns subsequently linked to violent and firearm related crimes.

- Important risk factors for having a high rate of crime related handguns per 1000 gun years of exposure included licensure as a pawnbroker and the percentage of sales denied because the purchasers were prohibited from owning guns.

- Other than local policy on tracing recovered crime guns, community level factors (crime rates and sociodemographics) were of little predictive value.

- Data already gathered at the federal level would permit screening and tentative identification of handgun retailers whose guns are disproportionately likely to be involved in violent and firearm related crimes.
Foundation, and grants from The Joyce Foundation and The Richard and Rhoda Goldman Fund. The study sponsors played no role in study design; in collection, analysis, and interpretation of data; in the writing of the report; or in the decision to submit the paper for publication.

Competing interests: none.

\section{REFERENCES}

1 Catalano SM. Criminal victimization, 2004. Washington, DC: Bureau of Justice Statistics, 2005, NCJ 205455.

2 Federal Bureau of Investigation. Crime in the United States, 2003. Washington, DC: Federal Bureau of Investigation, 2004

3 Harlow CW. Firearm use by offenders. Washington, DC: Bureau of Justice Statistics, 2001, NCJ 189369.

4 Scalia J. Federal firearm offenders, 1992-98. Washington, DC: Bureau of Justice Statistics, 2000, NCJ 180795

5 Bureau of Alcohol, Tobacco and Firearms. Following the gun: enforcing federal laws against firearms traffickers. Washington, DC: Bureau of Alcohol, Tobacco and Firearms, 2000.

6 Graduate Institute of International Studies. Small arms survey 2004. Oxford, UK: Oxford University Press, 2004:200.

7 Graduate Institute of International Studies. Small arms survey 2002: counting the human cost. Oxford, UK: Oxford University Press, 2002:135.

8 US Department of Justice, Office of the Inspector General, Evaluation and Inspections Division. Inspections of firearms dealers by the Bureau of Alcohol, Tobacco, Firearms and Explosives. Washington, DC: US Department of Justice, 2004, 1-2004-005

9 Bureau of Alcohol, Tobacco and Firearms. Crime gun trace reports (2000) Washington, DC: Bureau of Alcohol, Tobacco and Firearms, 2002.

10 Bureau of Alcohol, Tobacco and Firearms. Commerce in firearms in the United States. Washington, DC: Bureau of Alcohol, Tobacco and Firearms, 2000

11 Federal Bureau of Investigation. National Instant Criminal Background Check System (NICS): operations report (November 30, 1998-December 31, 1999). Washington, DC: Federal Bureau of Investigation, 2000.

12 National Rifle Association. White House plan nothing new, targets licensed, lawful dealers, Available at http://www.nraila.org/News/Read/ InTheNews.aspx?ID = 538 (accessed April 2000)

13 Wintemute GJ. Relationship between illegal use of handguns and handgun sales volume [research letter]. JAMA 2000;284:566-7.

14 Fjestad S. Blue book of gun values. Minneapolis, MN: Blue Book Publications, 2000.

15 Schwing N. 1998 Standard catalog of firearms: the collector's price \& reference guide. lola, WI: Krause Publications, 1998.

16 Wintemute GJ, Romero MP, Wright MA, et al. The life cycle of crime guns: a description based on guns recovered from young people in California. Ann Emerg Med 2004;43:733-42.

17 Wintemute GJ, Parham CA, Wright MA, et al. Weapons of choice: previous criminal history, later criminal activity, and firearm preference among legally authorized young adult purchasers of handguns. J Trauma 1998;44:155-60.

18 Bureau of Alcohol, Tobacco and Firearms. Gun shows: Brady checks and crime gun traces. Washington, DC: Bureau of Alcohol, Tobacco and Firearms, 1999.

19 Braga AA, Kennedy DM. Gun shows and the illegal diversion of firearms. Georgetown Public Pol Rev 2000;6:7-24

20 Bureau of Alcohol, Tobacco and Firearms. Operation Snapshot: an analysis of the retail regulated firearms industry. Washington, DC: Bureau of Alcohol, Tobacco and Firearms, 2000.

21 Violence Prevention Research Program. Handgun commerce in California, 1999. Sacramento, CA: Violence Prevention Research Program, 2002.

22 Bowling M, Lauver G, Hickman M, et al. Background checks for firearm transfers, 2002. Washington, DC: Bureau of Justice Statistics, 2003, NCJ 200116.

23 Pierce GL, Braga AA, Hyatt RRJ, et al. Characteristics and dynamics of illegal firearms markets: implications for a supply-side enforcement strategy. Justice Quarterly 2004;21:391-422.

24 California Justice Statistics Center. Available at http://ag.ca.gov/cjsc/ (accessed October 2005).

25 Scribner RA, MacKinnon DP, Dwyer JH. The risk of assaultive violence and alcohol availability in Los Angeles County. Am J Public Health 1995:85:335-40.

26 Gorman DM, Speer PW, Labouvie EW, et al. Risk of assaultive violence and alcohol availability in New Jersey. Am J Public Health 1998;88:97-100.

27 Sherman LW, Shaw JW, Rogan DP. The Kansas City gun experiment. Washington, DC: National Institute of Justice, 1995, NCJ 150855.

28 In: Wellford CF, Pepper JV, Petrie CV eds. Firearms and violence: a critical review. Washington, DC: The National Academies Press, 2004, 53-71, $221-$ 41

29 Wilson JQ. Crime and public policy. In: Wilson JQ, Petersilia J, eds. Crime San Francisco, CA: ICS Press, 1995:489-507.

30 McCullagh P, Nelder J. Generalized linear models. London, UK: Chapman \& Hall, 1989.

31 Wintemute GJ, Drake CM, Beaumont JJ, et al. Prior misdemeanor convictions as a risk factor for later violent and firearm-related criminal activity among authorized purchasers of handguns. JAMA 1998;280:2083-7.

32 Violence Prevention Research Program. Handgun commerce in California, 2000. Sacramento, CA: Violence Prevention Research Program, 2004

33 Ricker RA. Declaration in support of plaintiffs' opposition to defendant manufacturers' motion for summary judgment in People et al $v$ Arcadia 
Machine and Tool, Inc, et al. San Diego: Superior Court of California; Judicial Counsel Coordination Proceeding, 2003, No 4095

34 Cook PJ, Braga AA. Comprehensive firearms tracing: strategic and investigative uses of new data on firearms markets. Ariz Law Rev 2001:43:277-309.

35 Blackman PH. The limitations of ATF firearms tracing data for policymaking and homicide research. Proceedings of the Homicide Research Working Group, 1997-98. Washington, DC: National Institute of Justice, 1999.

36 Kleck G. ATF gun trace data and the role of organized gun trafficking in supplying guns to criminals. St Louis U Law Rev 1999;18:23-45.
37 General Accounting Office. Gun control: potential effects of next-day destruction of NICS background check records. Washington, DC: General Accounting Office, 2002.

38 United Nations General Assembly. The illicit trade in small arms and light weapons in all its aspects, United Nations General Assembly Res No 58/241, December 23, 2003.

39 Commission on Human Security. Human security now. New York, NY: Commission on Human Security, 2003.

40 World Health Organization. World Report on Violence and Health. Geneva, Switzerland: World Health Organization, 2002.

\section{bmjupdates+}

bmjupdates+ is a unique and free alerting service, designed to keep you up to date with the medical literature that is truly important to your practice.

bmjupdates+ will alert you to important new research and will provide you with the best new evidence concerning important advances in health care, tailored to your medical interests and time demands.

Where does the information come from?

bmjupdates+ applies an expert critical appraisal filter to over 100 top medical journals A panel of over 2000 physicians find the few 'must read' studies for each area of clinical interest

Sign up to receive your tailored email alerts, searching access and more...

www.bmjupdates.com 
reported. The measures described are largely those that have been implemented in Europe and North America. I hope that future revisions of this book will include studies examining measures being implemented in developing countries. This is a challenge to researchers working in developing countries to evaluate and publish findings on road safety measures that have been implemented in these countries.

M Khayes Injuries and Violence Prevention Department, World Health Organization khayesim@who.int

\section{CALENDAR}

2006 RoSPA Road Safety Congress: The road to safer behaviour

27 February to 1 March 2006, Blackpool England. Visit www.rospa.com/road/ index.htm for further information.

\section{Ontario Injury Prevention Conference 2006}

5 - 7 March, 2006, Toronto, Canada. The theme of the conference is "Injury Prevention through the Ages". Visit www.oipc.org for more information.

\section{International Winter Road Congress}

27 - 30 March 2006, Torino, Italy. Visit www.aipcr2006.it for further information for this meeting, organised by the World Road Association.

\section{Reducing Firearm-Related Mortality and Morbidity: Data to Action}

31 March - 1 April 2006, Durban, South Africa. The objectives of the conference are to examine how the collection and linkage of accurate and relevant data can assist in developing policies aimed at the prevention and reduction of firearm-related death and injuries, giving examples of good practice in this regard and identifying limitations and obstacles; and to examine how data is translated into action to prevent firearm related death and injury, giving examples of good practice, exploring the ways in which the social, political and economic environment either inhibits or facilitates the translation of data into action. Further information: http://tinyurl.com/as2rr.

\section{6th International Conference on Measuring the Burden of Injury}

1 April 2006, Durban, South Africa. The conference objectives are to promote the understanding, use and development of interdisciplinary health status and injury outcomes measures; to provide a forum for injury scientists from around the world to discuss emerging issues in the measuremen of injury outcomes; and to encourage a harmonized approach to injury outcomes research. For further information contact Stephen Luchter, sluchter@earthlink.net.

8th World Conference on Injury Prevention and Safety Promotion

2 - 5 April 2006, Durban, South Africa Further information and key dates: www. safety2006.info.

\section{International Society for Child and Adolescent Injury Prevention (ISCAIP) Bi-Annual Conference}

5 - 6 April 2006, Durban, South Africa. Further information: www.iscaip.net

\section{2nd International Seminar on Injury Research Methods}

6 - 7April 2006, Cape Town, South Africa. Organised by ECOSA-Eurosafe and the
Medical Research Council. More information from Saakje Mulder, s.mulder@consafe.nl, url: and www.mrc.ac.za/conference/ecosa/ index.htm.

15th International Safe Communities Conference: Creating a safer environment

9 - 11 April 2006, Cape Town, South Africa. Visit www.tinyurl.com/dn3sr for further information.

1st European Conference on Injury Prevention and Safety Promotion. Challenges for a Safer Europe

25 - 27 June 2006, Vienna, Austria. Further information: www.ecosa.org/csi/ecosa2003. Dnsf/events. Secretariat: Mrs Joke Broekhuizen, tel: + 31205114 513, www. secretariat@eurosafe.eu.com

\section{Australian Injury Prevention Network 8th National Injury Prevention Conference}

27 - 29 September 2006, Sydney, Australia. Visit www.aipn.com.au/conference.html for further information.

\section{CORRECTION}

An error occurred in the paper by Wintemute et al in last month's issue of the journal (Inj Prev 2005;11:357-63). The last sentence of the legend for figure 1 should read "Retailers with at least 100 sales annually are study subjects" and not "Retailers with approximately 100 sales annually are study subjects". 